\title{
Modal Dispositionalism and the (T) Axiom
}

\section{Matthew James Collier ${ }^{1}$ (D)}

Received: 5 May 2020 / Revised: 28 August 2020 / Accepted: 7 September 2020 /

Published online: 21 September 2020

(C) The Author(s) 2020

\begin{abstract}
Yates has recently argued that modal dispositionalism invalidates the (T) axiom. Both Yates and Allen have advanced responses to the objection: Yates's response proposes installing truth into the possibility biconditional, and Allen's response requires that all properties be construed as being essentially dispositional. I argue that supporters of Borghini and Williams's modal dispositionalist theory cannot accept these responses, given critical tenets of their theory. But, since these responses to the objection are the most plausible in the literature, I conclude that the threat that Borghini and Williams's modal dispositionalist theory invalidates the (T) axiom still looms large.
\end{abstract}

Keywords Modal Dispositionalism · Modal logic $\cdot$ Dispositions $\cdot$ Categorical and dispositional properties

\section{Introduction}

Modal dispositionalism (MD) semantically reduces, and ontologically explicates, possibility and necessity in terms of dispositionality. For MD, the dispositions of actual objects are taken as the truth-makers of modal claims. ${ }^{1}$ So, (roughly) some object's having the disposition to bring it about that $p$ makes-true the modal claim <possibly: $p>$.

Borghini and Williams's (2008) version of MD ('MD' shall refer exclusively to their

${ }^{1}$ For the most dominant possible worlds accounts, see Lewis (1986), Plantinga (1974) and Adams (1974).

Matthew James Collier

Matthew.collier@oriel.ox.ac.uk

1 Oriel College Oriel Square, Oxford OX1 4EW, UK 
theory) is the chief dispositionalist theory of concern here - however some of the points I raise generalize to other modal dispositionalist theories. ${ }^{2}$ The roadmap for this paper is the following: Section 2 sets up MD's ontology by explaining what dispositions and dispositional properties are, and provides an exposition of MD; and, section 3 examines an instance of MD's formal deficiency - specifically, I examine Yates's (2015) objection that, in the case of certain actualized necessities, modal dispositionalism's biconditionals for possibility and necessity invalidate the (T)-axiom, and I apply this objection to MD. To Yates's objection, I assess the two most plausible responses - one of which is owed to Yates (which is also provided in his (2015)), and the other to Allen (2017). I argue that both responses fail to save MD: crucially, they ignore critical aspects of MD. ${ }^{3}$ Indeed, Yates's response requires one to ignore MD's universal dispositionalist aim insofar as his response threatens to render dispositions redundant in MD's explication of modality, and Allen's response requires one either to ignore MD's naturalism or to accept that MD is - at best - ontologically bizarre or - at worst absurd. I conclude that neither of the two most plausible responses to Yates's objection are successful. Thus, MD should be rejected - whilst some modal logical axioms may be negotiable, some are not; certainly $(\mathrm{T})$ is not.

\section{Dispositions, Dispositional Properties and MD}

Let us Get a Grip on MD's Ontology. Dispositions, when under suitable stimulus conditions, ${ }^{4}$ manifest, and thereby produce or bring about certain states of affairs. ${ }^{5}$ That is to say, dispositions are considered abilities of objects to produce certain states of affairs, and so, standardly, dispositionality is understood in modal terms. ${ }^{6}$ Furthermore, (at least some) dispositions can manifest under multiple different stimulus conditions: for instance, a teacup will shatter if it is thrown against a hard surface - but, a teacup will also shatter if it is knocked with a mallet. Moreover, it is conventional for dispositions to be characterized by their manifestation-types - so, objects have dispositions for certain manifestations: for instance, a teacup's fragile disposition is characterised by its manifestation being such that, under the appropriate stimulus

\footnotetext{
2 There are two reasons for my choosing Borghini and Williams's MD: The first reason is that I regard it as one of the most easily understood dispositionalist accounts, and the second reason is that, by focussing on the resources wielded by MD, I can rebut various counter-objections to the chief objection raised in this paper: MD's invalidation of (T). For other MD-like accounts, see: Vetter (2015), Pruss (2011), Contessa (2010), Jacobs (2010), Bird (2007), Mumford (2004), Molnar (2003), and Ellis (2001).

${ }^{3}$ It is worth noting at the outset that neither Yates (2015) nor Allen (2017) are interested exclusively in MD, but rather in a more general modal dispositionalism. Indeed, Yates accepts that his solution to his objection entails a weak version of dispositionalism, and Allen is concerned with the extent to which modal dispositionalism requires a development of an implausible or an overly-complex ontology to maintain formal and material adequacy. However, I speak as if their responses specifically target MD, not only for simplicity's sake, but also to highlight that their responses to Yates's objection fail when applied to MD; thus, by treating their responses as specifically targeted at MD, I cast light upon the tenability of MD.

${ }^{4}$ The stimulus conditions are generally considered to consist solely of other dispositions.

${ }^{5}$ Here I follow Borghini and Williams's (2008) usage of states of affairs: that is, objects' having of properties are states of affairs, even if the relevant states of affairs fail to obtain. Thus, both manifested and unmanifested dispositions are construed in terms of states of affairs.

${ }^{6}$ Now, the term 'disposition' has many alternatives: for instance, 'power', 'potency', 'potentiality', 'capability', etc.... I just use 'disposition’ however.
} 
conditions, the teacup shatters. And so, a teacup's being fragile constitutes a disposition for shattering. Herein, I follow the above conventions.

The view that objects have dispositions through having certain properties is called dispositional realism. ${ }^{7}$ Central to dispositional realism is the notion that objects may possess dispositions that may never manifest. Thus, objects do not have certain dispositions because of the properties they had or will have, but instead because of the properties that they currently have. Importantly, there are two factions amongst the realists: the reductivists and the non-reductivists (/essentialists). Reductivists contend: the properties that ground dispositions are essentially non-dispositional (or categorical) - viz., non-dispositional properties ground dispositions and their manifestations. ${ }^{8}$ Nonreductivists, however, contend: essentially, irreducibly dispositional properties ground dispositions and their manifestations. ${ }^{9}$ So, essentially dispositional properties essentially dispose their object-bearers to behave in particular ways.

Now, Borghini and Williams (2008) are in the non-reductivist camp, but are agnostic over whether all properties are essentially dispositional; certainly, they do not explicitly endorse dispositional monism. ${ }^{10}$ For MD, it is sufficient for an object to have dispositions if it instantiates certain dispositional properties. ${ }^{11}$ But, Borghini and Williams make a distinction between dispositions and the dispositional properties that those dispositions are grounded by. They cite two reasons (and both are owed to Molnar (2003)): Firstly, (for some properties) from one dispositional property, many different manifestations can arise; and secondly, when combined with different combinations of dispositional properties, the same dispositional property can give rise to different manifestations. ${ }^{12}$ Moreover, Borghini and Williams (2008) maintain: dispositional properties are not extrinsic, but are intrinsic, and this is why dispositions need never manifest.

Now, as mentioned, dispositions are modal; and so, MD is not fully modally reductive. Borghini and Williams (2008: 33) maintain, however: "dispositions are something we need in our ontology anyway" whatever modal theory one endorses; so, they ask: why would one wish to reduce possibility to something else "if the dispositions can deal with [possibility] themselves?". MD, then, is the view that metaphysical modality is reducible to one modal notion: dispositionality.

And so, to analyse atomic possibility in terms of dispositionality, ${ }^{13} \mathrm{MD}$ provides the following biconditional:

\footnotetext{
${ }^{7}$ Here I follow Borghini and Williams (2008) in following Prior's (1985) characterisation of realism.

${ }^{8}$ I return to categorical properties when exploring MD's invalidation of (T).

${ }^{9}$ For defences of reductivism see: Lewis (1997), Armstrong (1997), Jackson (1995), Prior (1985), Jackson et al. (1982) and Mackie (1977). For defences of non-reductivism see: Bird (2007), Mumford (2004), Molnar (2003), Heil (2003), Ellis (2002) and Mellor (2000).

${ }^{10}$ Later I return to dispositional monism.

${ }^{11}$ It is worth noting that MD is neutral on the ontological status of dispositional properties: for instance, on MD, properties can be immanent universals or tropes. However, properties cannot be (as per Lewis (1986)) sets of individuals that reside in possible worlds.

12 The former case is entitled by Molnar (2003: 194) 'pleitropy' and the latter 'polygeny'.

13 Borghini and Williams (2008: 31) provide biconditionals besides the biconditional for atomic possibility e.g. they provide biconditionals for conjunctive, disjunctive and existentially quantified possibilities. However, these other biconditionals are not relevant here.
} 
(AP) For any atomic state of affairs, $S, S$ is possible $\leftrightarrow$ some actual objects have some dispositional properties $d_{1}, \ldots, d_{n}$, which ground some disposition $D$, which has as its manifestation, $S .{ }^{14}$

One can observe that AP coheres with dispositional realism's contention that dispositions need not ever actually manifest. Likewise, it need only be the case that some actual object bears $D$, for $S$ to be possible. Further, $S$ will, in addition to being possible, be actual, if $D$ manifests at some actual time, $t$; so, any actual state of affairs will also be possible given that the actual manifestations of dispositions ground actual states of affairs; and so, the ( $\mathrm{T}$ )-axiom, ' $\square \mathrm{A} \rightarrow \mathrm{A}$ ', is affirmed by MD.

Additionally, MD admits that if anything is a constituent of $D$ 's manifestation, that constituent is rendered possible by $D$ 's existence. Thus, for any relevant, say, "general" possibility, $D$ 's existence will ground the truth of that general possibility if it is a constituent of D's manifestation (Borghini and Williams 2008: 27). Thus, in addition to grounding the possibility of shattering, a teacup's being fragile grounds the following possibility: <possibly: at least one teacup exists $>$. ${ }^{15}$

And so, MD is an actualist and naturalist theory that semantically reduces and ontologically explicates possibility in terms of dispositionality: MD is actualist, because the dispositions of actual objects are the truth-makers of all possibility claims; and MD is naturalist, because objects' dispositions are spatiotemporal and causal.

\section{MD's Formal Deficiency: The Invalidation of (T)}

Now, there are (at least) two types of objection to MD. ${ }^{16}$ The first objection-type concerns MD's material deficiency, and asks: does MD ascribe the correct truth values to certain intuitively true modal claims? Those who answer negatively point to certain intuitively true unactualised possibilities, and demonstrate MD's inability to ascribe the correct truth values to claims pertaining to those possibilities by highlighting the fact that, on MD, such claims lack appropriate truth-makers. ${ }^{17}$ The second objection-type concerns MD's formal deficiency, and asks: does MD validate all desirable modal logical axioms? Those who answer negatively point to certain intuitively true actualised possibilities (or necessities), and demonstrate MD's inability to validate certain modal logical axioms, through the lack of truth-makers for claims pertaining to those possibilities.

\footnotetext{
${ }^{14}$ Strictly, AP should include the term 'iterated' (or ' $n$-iterated' where ' $n$ ' $=\geq 1$ ) such that AP reads '... some (iterated) dispositional properties...' and '....some (iterated) disposition...'. The notion of $n$-iterated-dispositions, however, is not relevant here. See Borghini and Williams (2008: 30-31) for an elucidation.

${ }^{15}$ An anonymous reviewer suggests that the point made within this paragraph might provide a way for MDists to avert problems concerning truthmakers for necessary truths that I discuss later. This might be true. But either way, I will be interested in mathematical truths and not just some set of necessary truths. I discuss the options for truthmakers for mathematical truths below.

${ }^{16}$ See Vance (2014) and Austin (2015) for alternative types of objection to MD-like theories.

${ }^{17}$ For objections of this type, to theories of MD's type, see Allen (2017), Vetter (2015), Wang (2015), Contessa (2010) and Cameron (2008).
} 
Here I argue for MD's formal deficiency. I argue: neither Yates's (2015) nor Allen's (2017) respective responses to Yates's (2015) objection that (T) is invalid on MD is successful. $^{18}$

Recall: for MD, since actual manifestations of dispositions ground actual states of affairs, any actual state of affairs will also be possible. Accordingly, this affirms (T): 'A $\rightarrow \diamond \mathrm{A}$ ' (or, contrapositively: ' $\square \mathrm{A} \rightarrow \mathrm{A}$ '). The truth of $(\mathrm{T})$ seems indisputable: were (T) not included in our modal logic, ' $\square \mathrm{A}$ ' would not express the claim 'necessarily: $A$ ', since the notion of it being necessary that $\mathrm{A}$ is the notion that it could not possibly be the case that not-A, and so A cannot be anything but true if $\square \mathrm{A}$ is true. Thus, it goes without saying that any modal theory should validate (T). ${ }^{19}$ However, as noted by Yates (2015), MD invalidates (T). To provide the objection, I use Yates's (2015: 413) biconditionals for the claims of the forms ' $\nabla \mathrm{A}$ ' and ' $\square \mathrm{A}$ ', which use second-order quantification over dispositions:

(Where $\left.{ }^{\prime} \exists D\right\rangle[\mathrm{p}](D)$ ' = 'there exists a disposition $D$ such that $D$ has $\mathrm{p}$ as its manifestation')

$$
\begin{aligned}
& \text { (POSS) } \diamond \mathrm{p} \leftrightarrow \exists D\rangle[\mathrm{p}](D) \\
& (\mathrm{NEC}) \square \mathrm{p} \leftrightarrow \neg \exists D\rangle[\neg \mathrm{p}](D) .{ }^{20}
\end{aligned}
$$

Now, consider the claim: ' $1+2=3$ '. By NEC, if ' $\neg \exists D\rangle\left[{ }^{\circ} \neg(1+2=3)^{\prime}\right](D)$ ' is true, then ' $1+2=3$ ' is necessarily true. Since this condition seems satisfied, we therefore get: ' $\square(1+2=3)$ '. This is the correct result: true mathematical propositions should be necessarily true. Moreover, since whatever is necessary is also possible, we also get: ' $\nabla(1+2=3)$ '. Now, by POSS, if ' $\exists D\rangle\left[{ }^{\circ} 1+2=3^{\prime}\right](D)$ ' is true, ' $1+2=3^{\prime}$ is possible. This condition, however, seems unsatisfied: specifically, there fails to exist an object with a disposition which has ' $1+2=3^{\prime}$ as its manifestation. Certainly, there exist dispositions that, if manifested, ' $1+2=3$ ' would be true - but this is distinct to there existing a particular disposition that grounds the truth of ' $1+2=3$ '. So, by POSS, we therefore get: ' $\neg \diamond(1+2=3$ )' (which, given ' $\neg \nabla A \leftrightarrow \square \neg A$ ', we also get: ' $\square \neg(1+2=3)$ ').

So, on MD, when considering ' $1+2=3$ ', we get two sets of claims: $\{$ ' $\square(1+2=3)$ ', $\left.' \neg \diamond(1+2=3)^{\prime}\right\}$ and $\left\{{ }^{\prime} \square \neg(1+2=3)\right.$ ', ' $\left.\diamond(1+2=3)^{\prime}\right\}$. Clearly then, (T) fails: ' $\square(1+2=3)$ $\rightarrow 1+2=3$ ' is invalid, since ' $\square \neg(1+2=3)$ ' is true, and ' $\square \neg(1+2=3)$ ' entails that necessarily ' $1+2=3$ ' is false; and ' $1+2=3 \rightarrow \diamond(1+2=3)$ ' is invalid, since ' $\neg \diamond(1+2=3)$ ' is true.

The problem, I believe, stems from the fact that the truth-makers for ' $1+2=3$ ' seem to be categorical properties. So, if this is the case, it is perhaps not surprising that claims like ' $1+2=3$ ' deliver odd results on MD's biconditionals - after all, MD's

\footnotetext{
${ }^{18}$ It is important to remember that Yates (2015) and Allen (2017) concern themselves with modal dispositionalist type theories, and not exclusively with Borghini and Williams's (2008) MD. Here I speak as if Yates and Allen are referring to MD, for simplicity, but also to show that some of their responses to Yates's objection miscarry given MD's specifics.

${ }_{20}^{19}$ This might not be quite right in perfect generality, if we admit impossible worlds into our modal theory.

Given the truth of the axiom: ' $\square \mathrm{A} \leftrightarrow \neg \diamond \neg \mathrm{A}$ ', NEC is a substitution instance of POSS.
} 
biconditionals analyse modal claims by appealing to dispositions, which, on MD, are exclusively ontologically supported by dispositional properties, not categorical properties. Thus, since, for MD, all modal claims are made-true by dispositions, which are grounded by dispositional properties, any claim that has categorical properties as a truth-maker can be used to demonstrate that MD invalidates (T).

Now, there are two plausible responses in the literature: one is owed to Yates (2015) and the other to Allen (2017). I argue that both responses fail.

The first response proposes installing truth into MD's biconditionals, so by stipulation (T) holds - here are the biconditionals (Yates 2015: 419):

$$
\begin{aligned}
& \left.\left(\mathrm{POSS}^{*}\right) \diamond \mathrm{p} \leftrightarrow\{\mathrm{p} \vee \exists D\rangle[\mathrm{p}](D)\right\} . \\
& \left.\left(\mathrm{NEC}^{*}\right) \square \mathrm{p} \leftrightarrow\{\mathrm{p} \wedge \neg \exists D\rangle[\neg \mathrm{p}](D)\right\} .
\end{aligned}
$$

So, since ' $1+2=3$ ' is true, ' $1+2=3$ ' is possible. Thence, $(\mathrm{T})$ holds.

Now, Yates (2015: 412) claims that "[he] see[s] no reason why" MDists should not "embrace [his] amendments" to the biconditionals. I do see why, however: installing truth into the biconditionals is tantamount to rejecting MD's core claim: i.e., that all modal facts are made-true by dispositions alone. Thus, MDists welcome this solution on pain of rejecting MD's principal tenet and thereby limiting dispositions' capacity to ground modality. Now, Yates does accept that his solution renders MD-like theories weak rather than strong. But, I am not as sanguine about adopting the solution as he is MDists, I argue, should not adopt the solution: installing truth into the biconditionals is not mere tinkering - Yates's solution requires a fundamental change to the nature of MD. ${ }^{21}$ Indeed, Yates's response here should seem odd to MDists: MDists wish to know why it is that claims such as ' $1+2=3$ ' are true and necessarily true, and MD should informatively explain this - indeed, MDists do not merely wish to know whether such claims simply are true, they wish to know why they are true. Certainly, on possible worlds accounts, truth is installed into the biconditionals: 'possibly: $\mathrm{p} \leftrightarrow$ at some world: p' and 'necessarily: $\mathrm{p} \leftrightarrow$ at all worlds: p'. However, I take it that part of MDists' aversion to possible worlds accounts of modality is precisely that truth is installed into the biconditionals (very often) with no further informative explanation for why, say, a certain proposition just so happens to be true at some world. It seems that a virtue of MD is that, through its actualism, naturalism, and dispositionalism, MDists can provide true modal claims with informative explanations for why they are true: there is some causal and spatiotemporal explanation for why <possibly: $p>$ is true - that possibility claim is true, not simply by virtue of its being true at the world, but by virtue of causal and spatiotemporal features of the world, namely, dispositions. Indeed, it seems (at least part of) the reason for propounding MD is to provide an informative explanation of why certain claims are necessarily true, but if we can now simply say that (at least some) necessity claims are true if their corresponding non-modal claims are true with no positive dispositionalist grounding to account for their being true, dispositions seem

\footnotetext{
${ }^{21}$ Again, it is worth remembering that Yates (2015) is not specifically interested in MD; however, here I am treating his response as specifically targeted at MD for the reasons I give above.
} 
redundant. And, if dispositions are now not required to do the work that MDists thought they did, why should MDists not provide a simpler account, and analyse all modal claims purely in terms of truth? That is, why should MDists not provide the following biconditionals?

$$
\begin{aligned}
& \left(\mathrm{POSS}^{* *}\right) \diamond \mathrm{p} \leftrightarrow\{\mathrm{p}\} . \\
& \left(\mathrm{NEC}^{* *}\right) \square \mathrm{p} \leftrightarrow\{\mathrm{p} \wedge \neg(\neg \mathrm{p})\} .
\end{aligned}
$$

The answer from MDists, I take it, would be: Part of our motivation for positing MD, and part of our reason for rejecting possible worlds, is that we wish to provide a causal and spatiotemporal (that is: a naturalist) explanation of why it is that certain true claims are necessarily true: analysing modality in terms of dispositions allows us to provide such an explanation. Necessary truths should not float free from, or be prior to, or be more basic than, dispositions; dispositions should be more basic than, or be prior to, or not float free from, necessary truths. Thus, if MDists were happy to accept Yates's conclusion that MD cannot account for, say, mathematical necessities in terms of dispositions, then rather than accept Yates's amendment of installing truth into the biconditionals to account for mathematical truths, it seems MDists should instead concern themselves exclusively with providing truthmakers for, say, nomic possibilities and necessities. $^{22}$

Now, one might contend that Yates's modal distinction which entails that necessary mathematical truths are not grounded by dispositions is justifiable; indeed, Yates only revises the biconditional to deal with such necessary truths. ${ }^{23} \mathrm{I}$ am unconvinced here: certainly, it is sometimes claimed that necessary facts are brute; but, as I note above, I take it that the MDist would reject this claim on explanatory grounds. But, even if such a distinction can be justified, such that MDists can accept that some necessities are brute, and so can accept that their naturalist explanatory project does not extend to such necessities, it is unclear that such a distinction would render the theory preferable to the possible worlds framework, all things considered: sure, MD might be able to provide a more satisfactory explanation of why, say, it is possible that I be a concert pianist, but a possible worlds theory can provide theoretical unity. It is at best unclear which virtue is preferable.

Perhaps, however, it could be contended that the truth claims within the respective right-halves of the biconditionals POSS* and NEC* (and POSS** and $\mathrm{NEC}^{* *}$ ) are true by virtue of the actual manifestations of dispositions. ${ }^{24}$ Certainly, one may attempt to provide a dispositionalist account of, say, mathematical truths - and I consider this strategy below - however, it is then unclear why truth is installed into the biconditionals' respective right-halves; if, for instance, the claim ' $\mathrm{p}$ ' within ' $\{\mathrm{p} \vee \exists D\rangle[\mathrm{p}](D)\}$ '

\footnotetext{
${ }^{22}$ Now, Borghini and Williams (2008: 21-22, fn2) note that they are content with not providing an account of logical necessity - however, mathematical necessity falls within the scope metaphysical necessity, and Borghini and Williams (2008: 21, fn2) claim that they wish to account for metaphysical possibility. Thus, if they cannot account for mathematical necessity, their theory fails to do what they wish it to do.

${ }^{23}$ I thank an anonymous reviewer for pressing me on this point.

${ }^{24}$ I thank an anonymous reviewer for this suggestion.
} 
is true by virtue of an actual manifestation of a disposition, then why should the ' $p$ ' be included in the biconditional at all? The 'p' would be redundant. ${ }^{25}$

For these reasons, then, I believe Yates's response is not available to the MDist.

\begin{abstract}
${ }^{25}$ An anonymous reviewer suggests that an indispensability argument (for examples, see Quine (1976, 1980a, 1980b, 1981a, 1981b) and Putnam (1979a, 1979b)) might be called upon such that MD's posited dispositions act as (indirect) truthmakers for mathematical claims via our best natural science - that is, MD's dispositions make true our best natural science, and our best natural science requires the truths of mathematical claims, and so MD's dispositions are indirect truthmakers for mathematical claims. Here is the reviewer:

"Since the dispositions postulated by MD act as truth makers for our best scientific theory and that theory requires the existence of mathematical ontology which determines necessary mathematical truths (or else, that our scientific theory somehow determines that mathematical truths hold without the extra mathematical ontology), then the physical dispositions indirectly determine the mathematical necessities. ... Of course, it is not generally true that the claim that ' $\mathrm{X}$ determines the truth of $\mathrm{Y}$ which requires $\mathrm{Z}$ ' entails that ' $\mathrm{Z}$ is true in virtue of $X$ '. But if we take on board the MD perspective that there isn't anything else to make $Z$ true, then the MD theorists have given a way in which the class of $Z$ truths (maths) are dependent on $X$ (physical or natural dispositions), which was what they needed. So this response is consistent with MD, although it could not be used in an argument for it without begging the question".

This response is certainly fascinating, and certainly warrants in-depth discussion. Indeed, a full defence of the claim that our best natural science requires the real existence of mathematical objects which determine mathematical truths would be required, which would depend in part upon the soundness of an indispensability argument about mathematical objects - and this is no easy task. (For an excellent introduction to indispensability arguments, see Colyvan (2019)). Moreover, the perhaps weaker claim that our best natural science determines mathematical truths, but does not require the real existence of mathematical objects, would need to admit of a full defence, if the stronger claim were not held - indeed, some argument might have to be given as to why, say, natural science rules out an error theory of mathematical claims; that is, natural science might have to exclude the possibility that mathematics is simply a useful, but strictly speaking false, theory (assuming mathematics is not simply a useful, but false, theory). But, at any rate, it seems like there is a huge amount that needs to be done here - all of it fascinating, but I think an in-depth discussion warrants a separate paper.
\end{abstract}

But, even if all the above were worked out there might still be a problem with this response. Even if it is true that our best natural science requires the existence of real mathematical objects which determine mathematical truths, or that our best natural science determines mathematical truths without the need for realist mathematical ontology, and the dispositions posited by MD act as truthmakers for our best natural science, it seems there will still be mathematical truths that are not required by our best natural science and thus the dispositions posited by MD are not ultimately or indirectly truthmakers for those truths. For instance, take the claim that the foundation of mathematics is set theory. Assume this is true. Let us suppose that the axioms of ZFC are true. Does our best natural science require the truths of the axioms of ZFC? Well, if the foundation of mathematics can be taken to be non-set theoretic, but category theoretic instead, and so all mathematics can be done with category theory instead of with set theory (or at least all the mathematics required by our best natural science can be done with either theory), then science will not require the truths of certain mathematical claims: for example, claims concerning the foundation of mathematics. That is, if our best natural science is neutral over whether set theory or category theory is the foundation of mathematics (since either theory can be used for all the mathematics required by our best natural science), then our best natural science does not require, say, set theory to be true and category theory to be false; and, the antecedent in this conditional seems right (indeed, it would be odd if our best natural science were not neutral on claims concerning, say, the nature of the cardinality of sets). However, it might be that the mathematics required by our best natural science entails that set theory is the foundation of mathematics, if necessarily set theory is the foundation of mathematics. But, then, it seems that we are back at the original problem: sure, there is perhaps no disposition which has as its manifestation the falsity of the claim that set theory is the foundation of mathematics, but what is the truthmaker for that claim so that, say, ZFC possible? The truthmaker(s) cannot indirectly make true that claim via our best natural science, since our best natural science is neutral on the truth of that claim; thus, we have to look elsewhere. Below, I explore some ontological options for the truthmakers of necessary mathematical truths.

Now, I have not done full justice to the reviewer's suggestion, but I hope to have shown that, despite its being a fascinating response, it will be no easy task in the first instance, and in the second, it may not even give the MDist what he needs after all: there may well be mathematical truths that are still not rendered possible. 
So, let us examine the second response, suggested by Allen (2017). Her response, in essence, is as follows: MDists should ontologically construe all properties as essentially dispositional properties; that is, to espouse, what I referred to earlier as, dispositional monism. Now, Wang (2015: 456) claims: "defender[s] of essentially dispositional properties need not ban categorical properties". But, to avoid invalidating (T), MDists may have to. ${ }^{26}$ So, paradigmatic categorical properties are now taken to be dispositional properties which support dispositions that, following Hütteman's (2013) terminology, continuously manifest. Thus, the truthmaker for ' $1+2=3$ ' is a continuously manifesting disposition, which is grounded by certain dispositional properties. But, one must ask: which objects have these dispositional properties? The first option is to say: all objects. This seems absurd, however: indeed, (without calling upon merely ad hoc reasons) why do I, my cat and my laptop each have dispositional properties that support a continuouslymanifesting disposition for ' $1+2=3$ '? Thus, we must move to the second option, which is to say: some objects. ${ }^{27}$ At this point Allen provides two ontological options, which both - she believes - help MD validate (T). Now, strictly speaking, Allen is correct here, both options do validate (T) - I do not deny that, like I did not deny that Yates's response validated (T). But, I do argue, in the way that I argued against Yates's response, that Allen's prescribed solutions validate (T) only at a high cost to MD. Let us examine Allen's ontological options.

The first option Allen sketches is to claim that numbers, as abstracta, instantiate certain dispositional properties that ground certain dispositions. So, the dispositional properties of the abstract mathematical objects, 1, 2 and 3, when combined, produce the continuously-manifesting-disposition that make-true the claim: ' $1+$ $2=3$ '. Now, Allen briefly mentions that, whilst a Platonist about dispositions might welcome this suggestion, an Aristotelian might not - and arguably, MDists are Aristotelians. ${ }^{28}$ But, there is, however, a sufficiently strong objection to Allen's first suggestion, which, I believe, demonstrates why MDists should not adopt such an ontological construal of mathematical objects (or at any rate should be rather cautious about adopting such an ontological picture). Specifically, this option, I argue, jars with MD's naturalism. ${ }^{29}$ Naturalism is the view that objects' dispositions are spatiotemporal and causal. Now, since abstracta are not spatiotemporal, it is reasonable to suppose that neither are their dispositions, if they have any. Moreover, it is conventional to regard abstracta as causally inert, that is, abstract entitles are non-causal; and, since the entities are non-causal, it is reasonable to suppose that neither are their dispositions, (again) if they have any. ${ }^{30}$ So, I argue: MDists are permitted to use the dispositions of numbers, which are taken as abstract entities, to ground mathematical necessities, only if they are willing to violate MD's naturalism - a core feature of MD. Of course, MDists are at liberty, for a price, to

\footnotetext{
${ }^{26}$ Now, strictly speaking, Wang may be correct: MDists could espouse a dual ontology: i.e. every categorical property has a dispositional counterpart. This, however, delivers an unnecessarily bloated ontology.

${ }_{27}$ Allen (2015: 39) notes that Vetter hinted at this response when replying to a paper on 26th November 2014, University of Oxford.

${ }^{28}$ For an elaboration of Aristotelianism in mathematics, see Mendell (2004).

${ }^{29}$ My objection is not entirely distinct from Aristotelianism, since Aristotelianism allows MD to be naturalist.

${ }^{30}$ See Rosen (2017) on the (non-)causal powers of abstracta.
} 
violate their naturalism - indeed, often the point of raising objections to theories and proposals is to better understand the costs involved in adopting those theories and proposals. However, it seems, to me at least, that since naturalism is such a core feature of MD's account of modality, permitting certain violations of naturalism, at best, presents a high price for MDists to pay, and, at worst, distorts MD to the extent that it no longer sufficiently resembles Borghini and Williams's original theory.

So, we have Allen's second ontological option: adopt physicalism about numbers that is, numbers existentially depend upon actual, concrete objects. So, the constantlymanifesting dispositions of (at least some) concrete objects make-true mathematical necessities. This view - although congruous with MD's naturalism - is certainly, I believe, unusual and antiquated (and plausibly antiquated for a good reason (although, I do not think that something's merely being antiquated is reason in itself to reject that something!)). ${ }^{31}$ It additionally seems that we have returned to the question: which objects have the relevant dispositions to ground mathematical necessities? Indeed, we originally thought it absurd that all objects have dispositions that ground mathematical necessities, so if MDists agree with that being absurd, they must now claim that only some concrete objects have dispositions that ground mathematical necessities. But this latter claim, I believe, seems more absurd than the former: why is it that members of one concrete object-type, and not members of another, have dispositions that ground mathematical necessities? Surely it would seem extremely odd that certain concrete objects have certain dispositions that ground mathematical necessities and certain other concrete objects do not. ${ }^{32}$ So, I argue: if MDists adopt physicalism about numbers, their theory is at best extremely bizarre and at worst absurd. Now, accepting either consequence is perhaps a price worth paying; but, since I am not an MDist, the price is not mine to pay, and, at any rate, MDists will have a better understanding of how large their purses are. ${ }^{33}$

And so: contra Allen, both ontological options, I believe, fail, or at least present substantial costs; thus, this second response, I believe, is also unavailable to MDists or at least is available only at a high price.

Therefore, since both the most plausible responses to MD's invalidation of $(\mathrm{T})$ are unsuccessful (or at least present rather high costs), MD should be rejected (or the cost better be demonstrated to be worth it). Unlike perhaps some logical axioms, rejecting (T) is non-negotiable. ${ }^{34}$

\footnotetext{
${ }^{31}$ See Mill (1843) for a defence of a similar ontological account of numbers.

${ }^{32}$ Now, some may think that one, albeit not physical but concrete, object grounds mathematical necessities: God. I am very sympathetic to this suggestion (see Leftow (2012) for an exploration of this topic and related issues). However, it should be obvious that unless God is taken to be a spatiotemporal object - or at any rate, a natural object - MDists should reject such a suggestion.

${ }^{33}$ An anonymous reviewer suggests that the proposal in footnote 25 may be applied here. Again, the same problems I mentioned therein arise. The reviewer also suggests that maybe necessary mathematical truths are "determined by dispositions belonging to worlds". Now, I am unsure what to make of this suggestion: if the point is that the universe's dispositions ground necessary mathematical truths, taking the universe as an object, we can ask: which parts of that object have the dispositional properties that support the universe's disposition(s) to determine necessary mathematical truths? That is, we are back at the original question: do all parts of the universe have dispositional properties that support a disposition that determines necessary mathematical truths or do only some?

${ }^{34}$ For instance, Borghini and Williams (2008: 32, fn.28) explicitly reject axiom-(4).
} 
Acknowledgements I would like to thank Farbod Akhlaghi, Sam Speight and Martin Pickup for very kindly providing me with comments on earlier drafts of this paper.

Open Access This article is licensed under a Creative Commons Attribution 4.0 International License, which permits use, sharing, adaptation, distribution and reproduction in any medium or format, as long as you give appropriate credit to the original author(s) and the source, provide a link to the Creative Commons licence, and indicate if changes were made. The images or other third party material in this article are included in the article's Creative Commons licence, unless indicated otherwise in a credit line to the material. If material is not included in the article's Creative Commons licence and your intended use is not permitted by statutory regulation or exceeds the permitted use, you will need to obtain permission directly from the copyright holder. To view a copy of this licence, visit http://creativecommons.org/licenses/by/4.0/.

\section{References}

Adams, R. (1974). Theories of actuality. Noûs, 8, 211-231.

Allen, S. R. (2017). From possibility to properties? Or from properties to possibility? Philosophy, 92(1), 21-49.

Armstrong, D. M. (1997). A world of states of affairs. Cambridge: Cambridge University Press.

Austin, C. J. (2015). The Truthmaking argument against Dispositionalism. Ratio, 28(3), 271-285.

Bird, A. (2007). Nature's metaphysics. Oxford: Oxford University Press.

Borghini, A., \& Williams, N. E. (2008). A dispositional theory of possibility. Dialectica, 62(1), 21-41.

Cameron, R. (2008). Truthmakers and modality. Synthese, 164, 261-280.

Colyvan, M., 2019. Indispensability arguments in the philosophy of mathematics. [online]. Stanford Encylopedia of Philosophy. E. N. Zalta ed. available at: <https://plato.stanford.edu/entries/mathphilindis/> [Accessed 30 July 2020].

Contessa, G. (2010). Modal Truthmakers and two varieties of Actualism. Synthese, 174(3), 341-353.

Ellis, B. (2002). The philosophy of nature - A guide to the new essentialism. Montreal: McGill-Queen's University Press.

Ellis, B. (2001). Scientific Essentialism. New York: Cambridge University Press.

Heil, J. (2003). From an ontological point of view. New York: Oxford University Press.

Hütteman, A. (2013). A disposition-based process-theory of causation. In S. Mumford \& M. Tugby (Eds.), Metaphysics of science (pp. 101-122). Oxford: Oxford University Press.

Jackson, F. (1995). From metaphysics to ethics: A Defence of conceptual analysis. New York: Oxford University Press.

Jackson, F., Prior, E., \& Pargetter, R. (1982). Three theses about dispositions. American Philosophical Quarterly, 19, 251-256.

Jacobs, J. D. (2010). A powers theory of modality: Or, how I learned to stop worrying and reject possible worlds. Philosophical Studies, 151(2), 227-248.

Leftow, B. (2012). God and necessity. Oxford: Oxford University Press.

Lewis, D. K. (1997). Finkish dispositions. Reprinted. In Papers in Metaphysics and Epistemology (Vol. 1999, pp. 133-151). New York: Cambridge University Press.

Lewis, D. K. (1986). On the Plurality of Worlds. Oxford: Clarendon Press.

Mackie, J. L., 1977. Dispositions, grounds, and causes. Reprinted in: R. Tuomela, ed., Dispositions. Dordrecht: D. Reidel Publishing. 1978. Pp. 99-107.

Mellor, D. H. (2000). The semantics and ontology of dispositions. Mind, 109, 757-780.

Mendell, H., 2004. Aristotle and mathematics. [online] Stanford Encylopedia of Philosophy. E. N. Zalta ed. available at: <https://plato.stanford.edu/entries/aristotle-mathematics/\#7.1> [Accessed 14 April 2020].

Mill, J. S. (1843). A system of logic, ratiocinative and inductive. London: Longmans, Green and Company.

Molnar, G. (2003). Powers. New York: Oxford University Press.

Mumford, S. (2004). Laws in nature. London: Routledge.

Plantinga, A. (1974). The nature of necessity. Oxford: Oxford University Press.

Prior, E. (1985). Dispositions. Aberdeen: Aberdeen University Press.

Pruss, A. R. (2011). Actuality, possibility, and worlds. New York: Continuum.

Putnam, H., 1979a. What is mathematical truth. In: Mathematics Matter and Method: Philosophical Papers, Volume 1. 2nd ed, Cambridge: Cambridge University press, pp. 60-78. 
Putnam H.,-1979b. Philosophy of Logic. Reprinted in: Mathematics Matter and Method: Philosophical Papers, Volume 1. 2nd ed, Cambridge: Cambridge University Press, pp. 323-357.

Quine, W. V. O., 1976. Carnap and logical truth. Reprinted in: The Ways of Paradox and Other Essays. Revised ed, Cambridge, MA: Harvard University press, pp. 107-132.

Quine, W. V. O. (1980a). On What There Is. Reprinted. In From a Logical Point of View (2nd ed., pp. 1-19). Cambridge, MA: Harvard University Press.

Quine, W. V. O. (1980b). Two Dogmas of Empiricism. Reprinted. In From a Logical Point of View (2nd ed., pp. 20-46). Cambridge, MA: Harvard University Press.

Quine, W. V. O. (1981a). Things and Their Place in Theories. In Theories and Things (pp. 1-23). Cambridge, MA: Harvard University Press.

Quine, W. V. O. (1981b). Success and Limits of Mathematization. In Theories and Things (pp. 148-155). Cambridge, MA: Harvard University Press.

Rosen G., 2017. Abstract Objects. [Online] Stanford Encylopedia of Philosophy. E. N. Zalta ed. Available at: $<$ https://plato.stanford.edu/entries/abstract-objects/> [Accessed: 5 September 2017].

Vance, C., 2014. Dispositional Modal Truthmakers and the Necessary Origin Philosophia 41, pp. 1111-1127.

Vetter, B. (2015). Potentiality. Oxford: Oxford University Press.

Wang, J. (2015). The modal limits of Dispositionalism. Noûs, 49(3), 454-469.

Yates, D. (2015). Dispositionalism and the modal operators. Philosophy and Phenomenological Research, 91(2), 411-424.

Publisher's Note Springer Nature remains neutral with regard to jurisdictional claims in published maps and institutional affiliations. 